\title{
Deterrence of Punitive Measures on Collusive Bidding in the Construction Sector
}

\author{
Wenhui Zhu $\mathbb{D}^{1},{ }^{1}$ Yuhang Zheng $\mathbb{D}^{1},{ }^{1}$ Kunhui Ye $\mathbb{D D}^{2}{ }^{2}$ Qian Zhang $\mathbb{D}^{1,3}$ and Minjie Zhang ${ }^{10}$ \\ ${ }^{1}$ School of Management Science and Real Estate, Chongqing University, 83\# Shabei Street, Shapingba District, \\ Chongqing 400045, China \\ ${ }^{2}$ International Research Center for Sustainable Construction, Chongqing University, 83\# Shabei Street, Shapingba District, \\ Chongqing 400045, China \\ ${ }^{3}$ School of Built Environment, The University of New South Wales, \\ Australia West Wing Red Centre Building Kensington Campus, Sydney 1465, Australia
}

Correspondence should be addressed to Kunhui Ye; kunhui_ye@cqu.edu.cn

Received 23 March 2021; Revised 21 June 2021; Accepted 19 July 2021; Published 3 August 2021

Academic Editor: Lei Xie

Copyright (C) 2021 Wenhui Zhu et al. This is an open access article distributed under the Creative Commons Attribution License, which permits unrestricted use, distribution, and reproduction in any medium, provided the original work is properly cited.

Collusive bidding has been a deep-seated issue in the construction market for a long time. The strategies implemented by bid riggers are deliberate, interactive, and complex, suggesting that antitrust authorities have difficulty preventing collusive behaviors. Based on game payoff matrixes, this study proposes a system dynamics (SD) model to present the deterrence of punitive measures, namely the certainty of punishment (CoP) and the severity of punishment (SoP), on regular bidders' to-collude decision-making. Data were collected from the Chinese construction industry to test the proposed SD model. While the model was supported, the results indicate that the $\mathrm{CoP}$ has a greater impact than the SoP on deterring regular bidders from making to-collude decisions. Furthermore, these two punitive measures cannot be replaced by each other, given the same deterrence effects. Thus, the study demonstrates the usefulness of deterrence theory to inhibit collusive bidding in the construction sector. It also sheds some light on the formulation of competition policy from the perspective of deterrence.

\section{Introduction}

Bidding is a primary means of auctioning public goods worldwide [1-3]. Recently, this kind of auction has witnessed the proliferation of collusive bidding in many industries such as manufacturing, construction, and services [4-6]. As noted in previous studies, collusive bidding is notorious for charging a heavy toll on the soul of fair competition [7], damaging the interest of purchasers [8], and breaching the right of regular bidders [9-11]. Besides, the imperfect competition incurred by collusive bidding is unfavorable for industrial innovation, and it jeopardizes the sustainable growth of industry [12]. Most countries, including the US $[13,14]$, China [15-17], Australia $[9,18]$, the UK [19], and the Netherlands [12], have thus exhibited a strong ambition to thwart collusive bidding.
There are two kinds of approaches, preventive and punitive, for antitrust authorities to impose controls over the outbreak of collusive bidding [20,21]. The preventive approaches are ex ante, which entails establishing an efficient bidding system [22-25] and promoting bidders' ethical behaviors $[18,26]$. Previous studies have affirmed the effectiveness of inhibiting collusive bidding in different bid pricing systems $[27,28]$. The derived findings suggest that an efficient and transparent bidding system can normalize bidders' behaviors by rewarding the most eligible bidders [29]. By comparison, the promotion of bidders' ethics to alleviate collusion depends on whether the values and legal rules serve as the basis for competitive behaviors [30]. The punitive approaches are ex post, denoting antitrust authorities' determination of imposing financial fines and imprisonment on those bid riggers that have been identified 
[31]. On occasions, tailoring current bidding rules to fluctuating market conditions is impracticable, and the hedges that bid riggers take against the existing rules are often encountered [4, 32-34]. Consequently, the punitive approaches have gained antitrust authorities' closer attention in the manipulation of collusive bidding $[1,35]$.

The rationales for utilizing punitive approaches to deter susceptible bid riggers are releasing a strong signal of competition regulations to market players by detecting and punishing incumbent bid riggers [36]. Such reasoning resembles noncooperation in public goods games $[37,38]$, where the deterrence effects are determined by the certainty of punishment $(\mathrm{CoP})$ and the severity of punishment (SoP) [39]. The CoP refers to the success rate of detecting bid riggers over the projects that have gone through bidding procedures [40]. The SoP delineates the magnitude of fines that antitrust authorities impose on bid riggers [39]. While both play a due role in crime deterrence, many countries prefer to use the SoP to deter regular bidders from initiating collusion [41, 42]. Meanwhile, excessive punishment turns out to be a diminished deterrent effect, namely overdeterrence [43], and the CoP owns more complicated deterrence effects than the SoP [44-47]. Although previous studies have confirmed the values of punitive approaches to deter collusive bidding, little consensus has been reached hitherto.

Bid riggers are composed of two strands of actors: the convenor and participants. The less business competition caused by bid-rigging facilitates these two actors to enjoy a higher winning probability, motivating the convenor to fortify collusive relationships [9, 48, 49]. If bid-rigging benefits are larger than expected, the convenor will undertake collusive bidding. By contrast, the convenor may be reluctant to conduct collusive bidding if benefits from the collusion are not very attractive. Therefore, it is worth investigating what means prevent bid riggers, either the convenor or its participants, from making such a decision. Doing so can inhibit the launch of collusive bidding. While such a claim can be aware in the literature, previous studies have not made sufficient efforts to explore the deterrent difference between the CoP, the SoP, and a combination of both in hindering the occurrence of collusive bidding $[31,50,51]$.

In appreciating the research gaps presented above, this study aims to examine the deterrence of punitive measures on collusive bidding regarding the certainty and severity of punishment. A model is proposed to account for deterrencebased decision-making mechanisms from the angles of the convenor, participants, and antitrust authorities. We collected data from the Chinese construction context to test the effectiveness of the proposed model. To this end, the remainder of this article is structured as follows. Section 2 presents a review of deterrence theory and the essence of collusive bidding to lay a theoretical foundation for the study. Section 3 describes the establishment of a system dynamics model. Section 4 elaborates the simulation process. Section 5 summarizes the results and discusses the findings. Finally, the research conclusions and recommendations for future research are given in Section 6.

\section{Literature Review}

2.1. Deterrence Theory. Deterrence theory originated from the utilitarian doctrine of crime, and it views crime as making rational choices to strike a cost-benefit trade-off $[36,52]$. The benefits are concerned with the money they gain from crime. The costs involve the disqualification to participate in business competition, financial fines posed by antitrust authorities, and ruined reputations in the niche market. A punishment may enhance the total cost of crime to unacceptable levels, making criminals feel unnecessary and risky to launch another one. However, the crimes shall not pay the penalty if they eschew being detected. The main thoughts of deterrence related to criminal offending are that punitive measures deter individuals from conducting crime, and punishing offenders help deter other potential offenders. Thus, an experienced criminal knows to gauge crime costs by multiplying the certainty and severity of punishment. The larger the crime costs, the higher the deterrence, and the less the to-be crime in the market.

2.2. Attributes of Collusive Bidding. In economists' opinions, collusive bidding is a specific form of monopoly in the field of auction. Although collusive bidding is diversified, such as winner rotation [35] and price manipulation [53], they have in common the operation process. The convenor first searches for potential bidders and desires to establish a bidrigging group with them [13]. The success of doing so depends on whether both sides reach agreements on the incomes they are about to receive from the illegal competition. The convenor agrees to redistribute collusive profits among bid riggers in an effort to unify all participants for targeted projects [54-56]. Hence, there is a vacuum of competition between the convenor and their participants, favoring them to guarantee a high success rate of collusion [9].

Collusive bidding is a serious crime that undermines the cornerstone of auction mechanisms and has been known for social irresponsibility [57]. Due to the illegality nature, collusive behaviors must be concealed as far as possible $[54,55]$, forming an obstacle for antitrust authorities to detect them. Researchers have proposed several approaches to overcoming the obstacle, such as diagnosing the anomalies of bidding prices [56-58], identifying bidders' networks and their inherent relationships [59, 60], and applying machine learning methods for mapping bidders [61]. Nevertheless, these approaches appear to be end-of-pipe solutions as they rarely address the formation and complexity of collusive bidding [62]. Moreover, few of them spell out the benefits and costs of bid riggers and the extent to which society has to accept the negative impacts of collusive bidding [54]. In practice, signals of collusion are often released and intercepted by antitrust authorities. It is thus considered that whether antitrust authorities utilize the 
signals to deter future collusive bidding without consuming too many public resources.

\subsection{Deterring Collusive Bidding in Construction. An all-} pervasive distribution of collusive bidding results in market competition disorder and the shrinkage of social welfare. Construction work bidding is project-based, one-off, and locationless. Unsurprisingly, collusive bidding in the construction sector is becoming a key area of competition in policy discourse, and consequently, they spurred heated discussion on their regulations [63]. Given effective monitoring, mitigating collusive bidding is an overwhelming challenge in the construction sector $[8,64]$. As usual, antitrust authorities are responsible for encapsulating collusion-free scenarios to expedite construction business transactions $[41,65,66]$. In light of deterrence theory, it is considered valuable to use punitive approaches to deter bidders from making to-collude decisions. Thus, collusive bidding can be prevented at an earlier stage.

Deterrence theory has been applied to develop and improve measures for dealing with property crimes [67]. It functions as a cornerstone for examining the substitution between the certainty and severity of punishment in the area of collusive bidding [45]. For instance, in line with deterrence theory, Landes suggested that increasing the likelihood of being caught deter more usefully than those that enhance punishment, and thus, an optimal criterion to calculate the numerical size of fines deserves attention [68]. Connor and Lande argued that punishing bid riggers is inadequate to discourage conspiracies [69]. Posner applied deterrence theory to antitrust examination and recognized that the alternative relationship between the certainty and severity of punishment is still valid for deterring monopolies [42]. Seemingly, both the certainty and severity of punishment have different deterrence effects, and they are interchangeable [45]. Therefore, the study embraces a combination of them for further analysis.

\section{Model Development}

3.1. Game Analysis. According to the principle of deterrence, bid riggers' to-collude decision revolves around the cost-benefit trade-off. Therefore, a game model is proposed to reflect such a decision-making mechanism as follows:

(a) The convenor: Each collusive bidding has a nominal winner (say, the convenor), whose role is to maneuver the whole collusion process. Most of the convenor's efforts are in liaison with bid riggers to reach income-sharing agreements. The convenor anticipates profits from collusive bidding but still needs potentially to pay a fine for organizing collusive bidding and benefit fees to all participants $[70,71]$. Specifically, the convenor must count the cost for searching for and negotiating with bid riggers [72]. If their collusive bidding is affirmed, the convenor will be stripped of illegal incomes and punished for violating business competition. Since not all bid-rigging groups can be established as planned, the convenor might eventually assume a regular bidder role.

(b) Participants: Participants' main duties are implementing bidding strategies as required by the convenor. They request compensation for being nominally disqualifying from attending business competition [73].

(c) Antitrust authorities: Antitrust authorities have to input public resources to detect collusion [74], another type of social cost. The penalties that antitrust authorities receive can be deemed compensation for the generation of social costs caused by collusive bidding [39].

A total of 12 collusive scenarios (Table 1) were listed to differentiate situations in which the convenor undertakes collusion, participants are engaged in the collusion, and antitrust authorities' detection is effective. The table elaborates a benefits matrix for three actors involved in a collusive bidding case.

The probability of the convenor deciding to initiate collusive bidding is $x$; the probability of a participant deciding to participate in collusive bidding is $y$. The probability of regulations by antitrust authorities is $z$, and the success rate of detection is $k$. The expected benefits per actor (Table 2) are calculated using the benefits matrix shown in Table 1.

3.2. A System Dynamics Model. Based on the relationships between the convenor, participants, and antitrust authorities, a system dynamics (SD) model is established to simulate the effects of the certainty and severity of punishment on collusive bidding inhibition. The SD model has three subsystem modes, as shown in Figure 1. Each subsystem comprises one state variable, one rate variable, and several auxiliary variables to present actors' decisionmaking process. Thus, three state variables, three rate variables, seventeen auxiliary variables, and fourteen constants are synthesized into the SD model. We interviewed twelve experts to verify the proposed SD model. For simplicity, the verification process is briefly summarized in this section.

(a) Decision-making mode: bid riggers know to draw on past experiences to support decision-making. They will forecast the payoff of ongoing collusion cases using historical data. A mixture of income disparities (Table 2 ) and the previously made decisions determine the ratio reflecting the variation of decisionmaking.

(b) Profit calculation mode: collusive bidding increases the convenor's probability of being awarded contracts. Ceiling bid prices specified in tender documents are adopted as a benchmark to calculate the winning prices. Thereby, profits are calculated for collusive and noncollusive bidding.

(c) Punishment determination mode: punishment relates to the turnover of collusive bidding as 
TABLE 1: The benefit matrix for all actors.

\begin{tabular}{|c|c|c|c|c|c|c|}
\hline \multirow{2}{*}{\multicolumn{2}{|c|}{$\begin{array}{l}\text { Detecting collusive } \\
\text { bidding }\end{array}$}} & \multirow[b]{2}{*}{$\begin{array}{l}\text { Benefits per } \\
\text { subject }\end{array}$} & \multicolumn{2}{|c|}{ The convenor initiates collusive bidding } & \multicolumn{2}{|c|}{$\begin{array}{c}\text { The convenor does not initiate } \\
\text { bidding }\end{array}$} \\
\hline & & & $\begin{array}{l}\text { Participant decided to } \\
\text { participate in collusive } \\
\text { bidding }\end{array}$ & $\begin{array}{l}\text { Participant not } \\
\text { decided to } \\
\text { participate in } \\
\text { collusive } \\
\text { biddings } \\
\end{array}$ & $\begin{array}{c}\text { Participant } \\
\text { decided } \\
\text { to participate in } \\
\text { collusive } \\
\text { bidding }\end{array}$ & $\begin{array}{l}\text { Participant not } \\
\text { decided to } \\
\text { participate in } \\
\text { collusive } \\
\text { bidding } \\
\end{array}$ \\
\hline \multirow{6}{*}{$\begin{array}{l}\text { Antitrust authorities detect } \\
\text { collusive bidding }\end{array}$} & \multirow{3}{*}{ Success } & \multirow{4}{*}{$\begin{array}{l}\text { The convenor } \\
\text { Participants } \\
\text { Antitrust } \\
\text { authorities } \\
\text { The convenor }\end{array}$} & $-N_{p} G-F_{c}-C_{c}$ & $w P_{n}-C_{c}$ & $w P_{n}$ & $w P_{n}$ \\
\hline & & & $-F_{p}-C_{p}$ & 0 & $-C_{p}$ & 0 \\
\hline & & & $P_{c}-P_{n}+F_{c}+N_{p} F_{p}-C_{g}$ & $P_{c}-P_{n}-C_{g}$ & $P_{c}-P_{n}-C_{g}$ & $P_{c}-P_{n}-C_{g}$ \\
\hline & \multirow{3}{*}{ Failure } & & $P_{c}-N_{p} G-C_{c}$ & $w P_{n}-C_{c}$ & $w P_{n}$ & $w P_{n}$ \\
\hline & & Participants & $G-C_{p}$ & 0 & $-C_{p}$ & 0 \\
\hline & & $\begin{array}{c}\text { Antitrust } \\
\text { authorities }\end{array}$ & $P_{n}-P_{c}-C_{g}$ & $P_{c}-P_{n}-C_{g}$ & $P_{c}-P_{n}-C_{g}$ & $P_{c}-P_{n}-C_{g}$ \\
\hline \multirow{3}{*}{\multicolumn{2}{|c|}{$\begin{array}{l}\text { Antitrust authorities do not detect } \\
\text { collusive bidding }\end{array}$}} & The convenor & $P_{c}-N_{p} G-C_{c}$ & $w P_{n}-C_{c}$ & $w P_{n}$ & $w P_{n}$ \\
\hline & & Participants & $G-C_{p}$ & 0 & $-C_{p}$ & 0 \\
\hline & & $\begin{array}{c}\text { Antitrust } \\
\text { authorities }\end{array}$ & $P_{n}-P_{c}$ & $P_{c}-P_{n}$ & $P_{c}-P_{n}$ & $P_{c}-P_{n}$ \\
\hline
\end{tabular}

TABLE 2: Expected benefits for collusion decision.

\begin{tabular}{lcc}
\hline Subjects & Expected benefits for action decision & Expected benefits for inaction decision \\
\hline The convenor & $-k z y\left(P_{c}+F_{c}\right)+y\left(P_{c}-w P_{n}-N_{p} G\right)+w P_{n}-C_{c}$ & $w P_{n}$ \\
Participants & $-k x z\left(G+F_{p}\right)+x G-C_{p}$ & 0 \\
Antitrust authorities & $k x y\left(2 P_{c}-2 P_{n}+F_{c}+N_{p} F_{p}\right)-2 x y\left(P_{c}-P_{n}\right)-C_{g}$ & $1-2 x y\left(P_{c}-P_{n}\right)$ \\
\hline
\end{tabular}

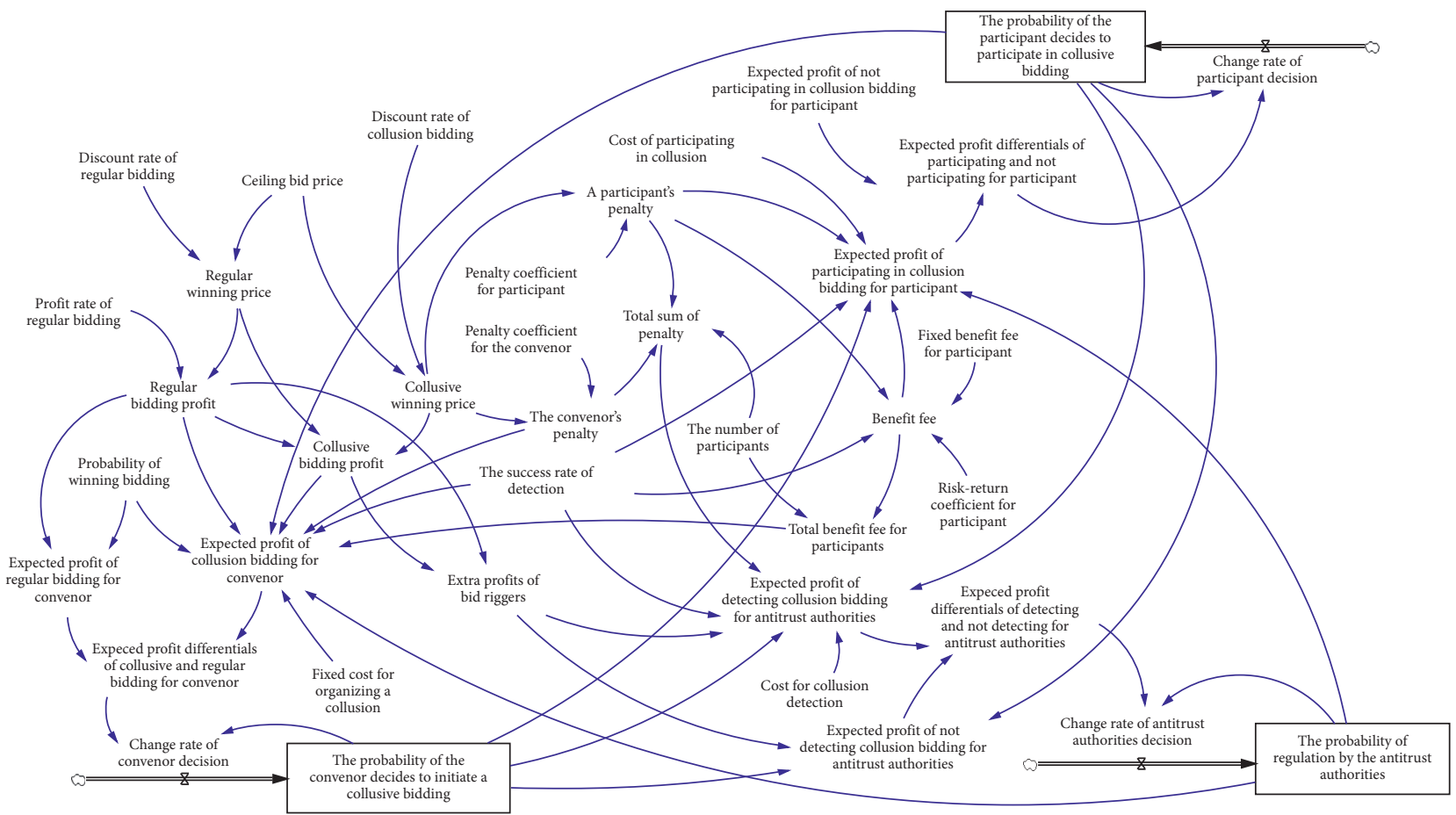

Figure 1: Stock and flow diagram for the dynamic system model. The dynamic system model combined with three subsystem modes simulates the decision-making process of different actors. In addition, the dynamic system model was established surrounding three key variables: "punishment coefficient for a participant", "punishment coefficient for the convenor", and "the success rate of detection". 
calculated by benchmarking prices with a punishment coefficient. The coefficient is calculated to mirror the different roles of the convenor and their participants in collusive bidding.

(d) Benefit fee calculation mode: participants are given a fixed payment or benefit fee. However, they might additionally claim fees depending on what fines they are going to face. The convenor has to pay all expenses to its participants to maintain the stability of bid-rigging groups.

\section{Simulation}

4.1. Parameter Setting and Data Collection. In the study, we interviewed eight professionals with considerable experience in construction business collusion to assign an initial value for the SD model. The interviewees were composed of one engineer, two consultants, three bidding agents, and two project managers. As the interviewees advised, a ceiling bid price is suitable to measure bidders' competitiveness. Those regular bidders ought to win the bid with the lowest price, usually $80 \%$ of the ceiling price. Thus, the discount rate of regular bidding (say, 0.8 ) was considered an initial value. In addition, the noncollusive bidders have a $20 \%$ chance of winning the bid, with an average return of $8 \%$. Illegal competition help bid riggers increase the bid price to $90 \%$ of the ceiling bid price. The scenario assumed here similarly appeared in some countries. As reported by Priemus, bid prices are increased by $8.8 \%$ as caused by collusion in the Netherlands [75]. Signor et al. revealed that the bid price increases by $20 \%$. Therefore, it is acceptable to develop the following equations [76]:

Regular winning price $=$ Ceiling bid price $\times$ Discount rate of regular bidding, where the initial rate is 0.8

Regular bidding profit $P_{n}=$ Regular winning price $\times$ Profit rate

Collusive winning price $=$ Ceiling bid price $\times$ Discount rate of regular bidding, where the initial rate is 0.9

Collusive bidding profit $P_{c}=$ Additional profits from collusive bidding + Regular profit $P_{n}$

Collusive winning profit $=$ Collusive winning price - Regular winning price + Regular profit

Additional profits $=$ Collusive winning price - Regular winning price

As the interviewees recalled, finding participants per collusive bidding case usually costs the convenor RMB 100 thousand (US\$13.6 thousand), and the benefit fee that the convenor delivers to its participants is a fixed benefit payment of about RMB 100 thousand (US $\$ 13.6$ thousand) and an additional fee that participants claim for risk compensation. The fixed payment covers the bidding expense, about RMB 5 thousand (US $\$ 0.68$ thousand). The additional fee can be calculated by multiplying the success rate of detection $k$ with potential punishment $F_{p}$.

Benefit fee $G=$ Fixed benefit fee + Additional fee
Additional fee $=$ Risk-return coefficient $T \times$ Expected punishment $E_{p}$

Expected punishment $E_{p}=$ Probability of successful detection $k \times$ Potential punishment $F_{p}$

We collected one hundred sixteen collusion cases and four media reports with detailed information from the Chinese construction industry for 2010-2017. The data analysis results reveal that those projects with a size of RMB 22 million (US\$3 million) are more intended for collusive bidding; participants in a collusive bidding team are on average thirteen. According to China's antitrust law, a punishment shall be imposed on bid riggers, depending on the punishment coefficient and the winning bid price. For example, the coefficient for the convenor $f_{c}$ is $1 \%$, and the coefficient for a participant $f_{p}$ is $0.5 \%$. Therefore, the amount of punishment is calculated as follows:

Convenor's punishment $F_{c}=$ Punishment coefficient for the convenor $f_{c} \times$ Winning bid price

Participant's punishment $F_{p}=$ Punishment coefficient for a participant $f_{p} \times$ Winning bid price

Vensim was used to build the subsystem flows and the entire SD model. Decision probabilities for the convenor, participants, and antitrust authorities fall in the range of $0-100 \%$ with an initial value of $50 \%$.

4.2. Simulation on the Certainty of Punishment. The simulation serves to detect how the certainty of punishment, or the success rate of detection, affects the convenor's decisionmaking. The system is assumed to set an initial value, where $f_{c}$ is $1 \%$ and $f_{p}$ is $0.5 \%$. The success rate of detection starts from 0 and increases by $0.1 \%$ per time until it reaches $100 \%$. The following four scenarios are included:

(a) Scenario 1: Given the SoP, the threshold for the success rate of detection is $30.3 \%$. If the success rate of detection is lower than $30.3 \%$, antitrust authorities have to detect all project bidding thoroughly. However, since the success rate of detection is low, the convenor can initiate collusive bidding and benefit from bid-rigging. As a result, their collusive willingness might surge to $100 \%$. The decisionmaking curves are shown in Figure 2, suggesting that deterrence may not be guaranteed when the success rate of detection is low.

(b) Scenario 2: Assumed that the success rate of detection increases to $30.3 \%$, antitrust authorities find it worthy of detecting collusion cases, which means that bid riggers' benefits will be shrunk, and "to-be" bid riggers will abandon collusion (Figure 3). Furthermore, with the success rate of detection soaring to $31.9 \%$ (Figure 4 ), antitrust authorities find it effective to deter and image no collusive bidding in the market. Due to the restricted budget of collusion detection, antitrust authorities will tend to undo detection frequency. 


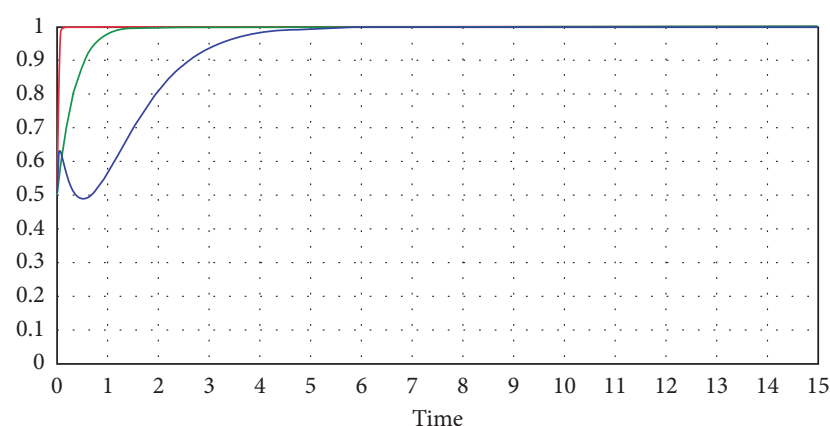

The probability that the convenor decides to initiate a collusive bidding $(x)$

The probability that the participant decides to participate in collusive bidding $(y)$

- The probability of regulation by antitrust authorities $(z)$

Figure 2: The curves of decision-making for three actors given the success rate of detection $k=30.0 \%$. The probability of regulation by antitrust authorities (red line) ascends to $100 \%$ immediately; the probability of collusive (green and blue lines) rises to $100 \%$ eventually.

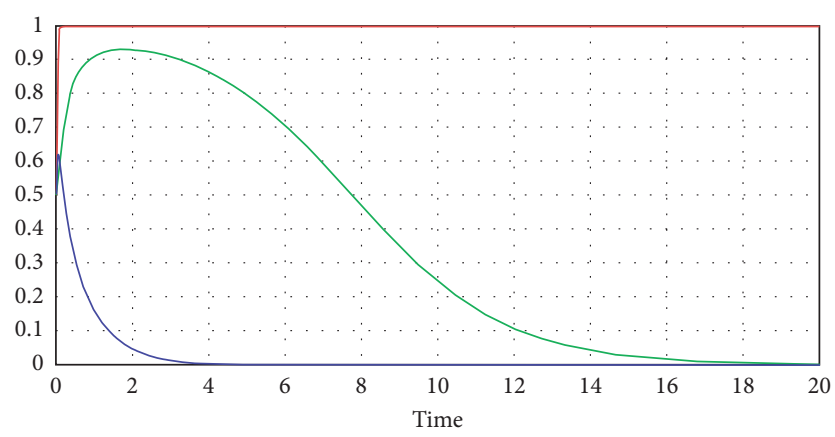

The probability that the convenor decides to initiate a collusive bidding $(x)$

The probability that the participant decides to participate in collusive bidding $(y)$

The probability of regulation by antitrust authorities $(z)$

Figure 3: The curves of decision-making for three actors given the success rate of detection $k=30.3 \%$. The probability of collusive (green and blue lines) that decreases to 0 keeps the probability of regulation by antitrust authorities (red line) at $100 \%$.

(c) Scenario 3: The success rate of detection is assumed 33.2\% (Figure 5). Antitrust authorities can deter collusion and relax the detection frequency as none of the collusive bidding has been encountered in the market. However, the market will again see the emergence of collusive bidding and the increase of governmental determination to detect bid-rigging. As Figure 6 indicates, with a further augment in the success rate of detection beyond $35.5 \%$, the market becomes stable after two regulation periods. The willingness to inhibit collusion erodes once again, at which point the market equilibrium is realized, and no more collusion appears.

(d) Scenario 4: The success rate of detection rises to $44.1 \%$ (Figure 7 ). Bid riggers find it impossible to

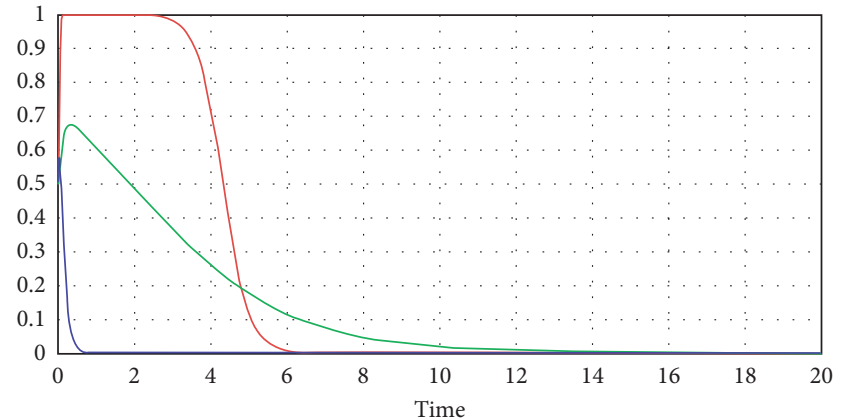

- The probability that the convenor decides to initiate a collusive bidding $(x)$

The probability that the participant decides to participate in collusive bidding $(y)$

_ The probability of regulation by antitrust authorities $(z)$

FIgURE 4: The curves of decision-making for three actors given the success rate of detection $k=31.9 \%$. The probability of the convenor initiates collusive bidding (blue line) decreases to 0 in a short time. This phenomenon indicates antitrust authorities (red line) can detect collusion cases effectively, while antitrust authorities will undo the detection after believing no collusive bidding practices in the market.

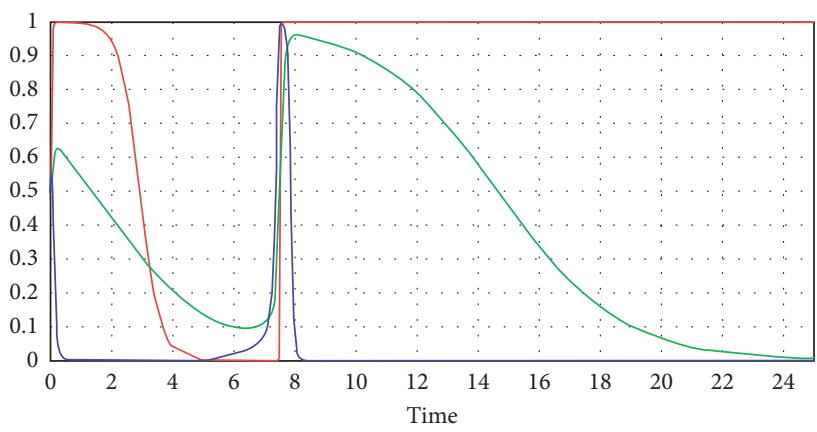

\footnotetext{
The probability that the convenor decides to initiate a collusive bidding $(x)$

The probability that the participant decides to participate in collusive bidding $(y)$

_ The probability of regulation by antitrust authorities $(z)$
}

FIgURE 5: The curves of decision-making for three actors given the success rate of detection $k=33.2 \%$. The time to maintain $100 \%$ detection by antitrust authorities (red line) is too short of establishing a new balance. The convenor (blue line) with participants (green line) restarts to initiate collusive bidding at the moment of no regulation. Therefore, antitrust authorities have to promote the probability of regulation to $100 \%$.

earn extra profits and prefer not to collude. Due to the withdrawal of the convenor, the number of potential bid riggers will also decrease. Antitrust authorities do not need to detect collusive bidding, and the detection frequency drops.

To summarize, the above four scenarios present a real situation in the construction market, namely (a) Scenario 1: strong willingness to detect but poor detecting capacity. (b) Scenario 2: long-time market detection with gentle pressure. 


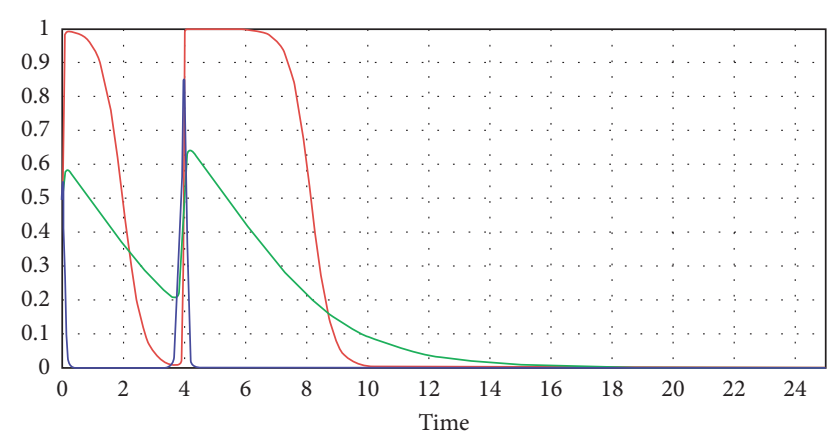

The probability that the convenor decides to initiate a collusive bidding $(x)$

- The probability that the participant decides to participate in collusive bidding $(y)$

— The probability of regulation by antitrust authorities $(z)$

FIGURE 6: The curves of decision-making for three actors given the success rate of detection $k=35.5 \%$. Like Figure 5, repeated governance is revealed again in this figure. However, due to a higher rate of successful detection, antitrust authorities do not need to maintain regulation probability (red line) to $100 \%$ until the end.

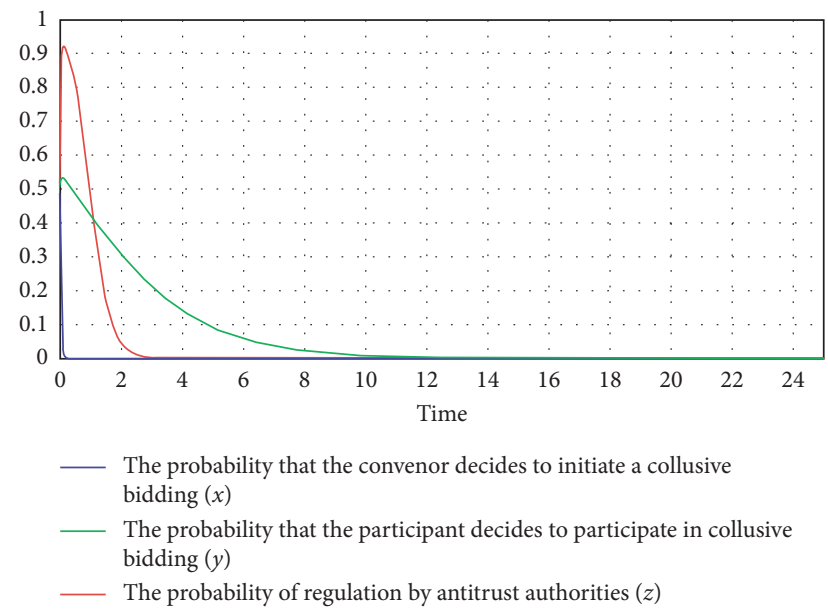

FIGURE 7: The curves of decision-making for three actors given the success rate of detection $k=44.1 \%$. Because of the high success rate of detection, the benefits of collusive bidding are unobtainable for bid riggers. The probability of collusive (green line and blue line) decreases to 0 directly, and antitrust authorities (red line) will undo the detection.

(c) Scenario 3: periodic regulation under moderate pressure. In practice, collusion cases draw social concerns, and antitrust authorities must immediately intensify detection to a higher rate. (d) Scenario 4: high detection frequency and no opportunities for bid riggers to survive.

4.3. Simulation on the Severity of Punishment. Collusive bidding will be significantly reduced when the success rate of detection reaches a threshold. However, it is unclear whether detection efforts are worth continuing and the SoP's roles in detecting collusive bidding. Therefore, the deterrence of the SoP is considered in this study. The SoP is quantified using two ranges of values: one is $0-100 \%$ for the convenor $f_{c}$, and the other is $0-50 \%$ for participants $f_{p}$. All of the simulations are based on the presumption that the success rate of detection $\left(k=30.3 \%, f_{c}=1 \%\right.$, and $\left.f_{p}=0.5 \%\right)$ can be guaranteed. Consequently, the success rate of detection and the corresponding punishment coefficients are connected to create a surface, as shown in Figure 8. Any point on the surface has the same deterrence effects, indicating that the success rate of detection that antitrust authorities take suffices to prevent the convenor and their participants from making a tocollude decision.

We took a point $\left(f_{c}, f_{p}\right)$ on the surface shown in Figure 8 with the same success rate of detection to form a concatenation; a contour plot of the surface projection is derived as given in Figure 9.

The results show the SoP for the convenor and their participants at any threshold of the success rate of detection as follows:

$$
f_{c}=-\frac{f_{p}}{26}+b
$$

where the constant (26) is the multiplication of participant number $N_{p}$ with the risk-return coefficient $T$ that participants claim. Thus, equation (1) is rewritten as follows:

$$
f_{c}=-\frac{f_{p}}{T \times N_{p}}+b
$$

where parameter $b$ refers to the linear intercept, showing a reversed correlation with the success rate of the detection threshold. We used the regression analysis to model the relationship between $b$ and $k$, with a goodness of fit $R^{2}=0.999$, as follows:

$$
k=\frac{0.003759}{\left(b / \sqrt{1+(-(1 / 26))^{2}}\right)+0.007079} .
$$

Equations (2) and (3) are further combined as follows:

$$
k=\frac{0.003759}{\left(\left(\left(T \times N_{p}\right) f_{p}+f\right) / \sqrt{1+\left(T \times N_{p}\right)^{2}}\right)+0.007079} \text {. }
$$

$T=2$ and $N_{\mathrm{p}}=13$ as indicated in the data collection section are substituted into equation (4). Hence, the relationship between the convenor's punishment coefficient, participants' punishment coefficient, and antitrust authorities' success rate of detection is rephrased as follows:

$$
k=\frac{0.003762}{f_{p}+0.03846 f_{c}+0.007083} .
$$

We defined the combination $\left(f_{c}, f_{p}\right)$ in equation (4) as the comprehensive punishment coefficient $f$ for a collusive team; then

$$
f=\frac{\left(T \times N_{p}\right) f_{p}+f_{c}}{\sqrt{1+\left(T \times N_{p}\right)^{2}}} .
$$




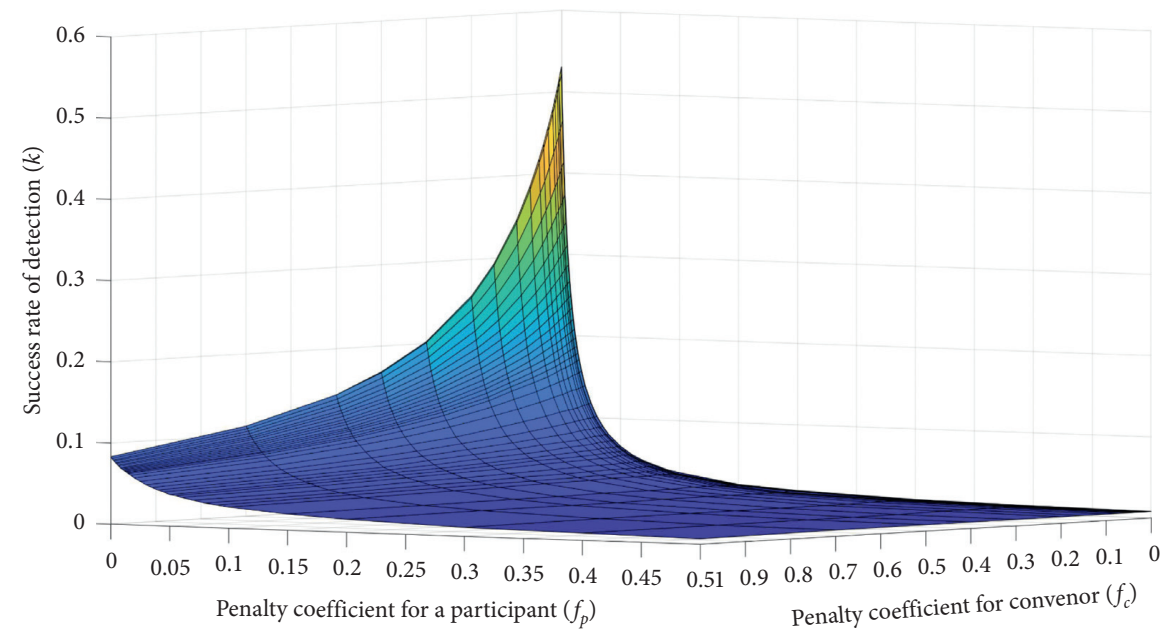

Figure 8: The surface diagram shows the combination of three coefficients (the success rate of detection $k$ punishment coefficient for the convenor $f_{c}$ and punishment coefficient for participant $f_{p}$ ), given a deterrence effect. Each point in the surface means the three coefficients that can reach an effective detection threshold $\left(k=30.3 \%, f_{c}=1 \%\right.$, and $\left.f_{p}=0.5 \%\right)$.

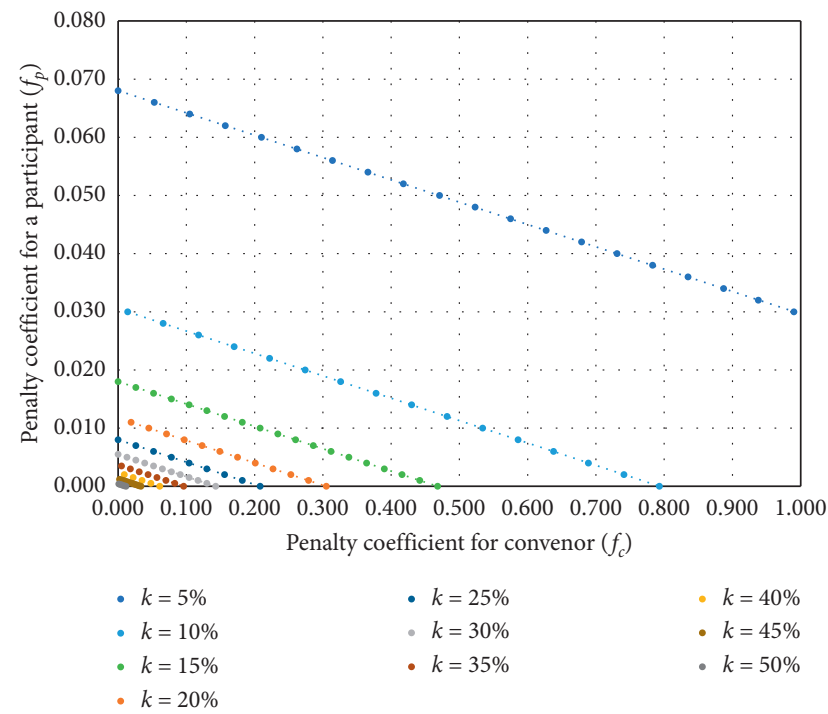

FIGURE 9: Contour plot of the surface projection shows the relationship of punishment coefficient between the convenor $f_{c}$ and their participant $f_{p}$ in the changing success rate of detection $k$, given a deterrence effect. All lines mirror a negative linear correlation between $f_{c}$ and $f_{p}$.

At this point, the relationship between the SoP and the success rate of detection exhibits an inverse proportional relationship as follows:

$$
k=\frac{0.003759}{f+0.007079} .
$$

It is noted that when the SoP is less than $5.423 \%$, the punishment coefficient will produce a better outcome than the success rate of detection. At that moment, the threshold of the success rate of detection will be $6.13 \%$, suggesting that when the SoP $f<5.423 \%$, an increase in the SoP increases the efficiency of regulation. Provided that $f$ equates to 0 , equation (7) will have the maximum value of 75.01, implying that the SoP reaches a maximum of 75.01 times detection frequency. Consequently, an increase in the SoP coincides with enhancing the success detection rate by 75 times. The sensitivity of the SoP is 24.22 times the sensitivity of the success rate of detection when $f_{c}=1 \%$ and $f_{p}=0.5 \%$ are synthesized to be $f=0.5380 \%$.

\section{Findings and Discussion}

5.1. Deterrence Effects of Punitive Measures. The above simulations are centered on three parameters: the SoP for the convenor, the SoP for its participants, and the CoP for antitrust authorities. As Figure 8 indicates, an increase in the CoP or the SoP promotes the deterrence effects on collusive bidding. Enhancing any of the three parameters will give rise to better deterrence effects, suggesting that collusive bidding can be deterred by implementing punitive measures. The results also indicate a mode of diminishing marginal deterrence effects. These findings demonstrate the usefulness of deterrence theory to address the role of punishment in inhibiting collusive bidding and outline many implications to policy formulation for improving competition regulation efficiency. Since deterrence theory has been mostly considered in criminal justice, this study can provide empirical evidence to link deterrence theory to collusive bidding [77-79]. Therefore, the research lays a theoretical foundation for future studies on the promotion of collusive bidding monitoring and the application of punitive measures to deter collusive bidding.

The research findings outline the threshold value of punitive measures, a reference to promote collusion regulations. The results show that the comprehensive punishment coefficient $f=0.5380 \%$ is smaller than the threshold $f=5.423 \%$, signifying that the SoP deserves wider applications in the Chinese construction market [44], echoing Connor and Lande's views [69]. As indicated by equation (1), an increase in the SoP for participants has better deterrence effects than that for the convenor. The reasons can be that 
the convenor has to bear participants' anticipated loss, and the convenor's expense ascends with more participants involved. The research findings indicate that participants' upscaling of collusion cost frustrates the convenor to implement collusive bidding. Therefore, antitrust authorities' efforts can be made towards participants to realize better deterrence. However, this does not mean that the convenor's role in collusive bidding may be overlooked $[80,81]$.

5.2. Replaceability between Two Punitive Measures. Previously, researchers employed the multiplication of the $\mathrm{CoP}$ by the SoP to gauge the deterrence effects of punitive measures [39], implying that the certainty and severity of punishment are replaceable in creating deterrence effects. However, the findings of the current study pose some challenges to previous studies. According to equation (7), the certainty and severity of punishment are in an adjusted inversely proportional relationship. This implies that these two measures are not fully replaceable in deterring collusive bidding.

As Feess et al. discussed, the reason for the weak replaceability is that an increase in the SoP facilitates antitrust authorities to reduce the CoP, while the overall deterrence effects stay unchanged [82]. When the success rate of detection decreases to 0 , the SoP becomes completely invalid. Simultaneously, when the SoP is 0 , deterrence effects may still be guaranteed by increasing the detection success rate to over $53.1 \%$. Thus, the severity and certainty of punishment are not fully substitutable for each other. As Figure 8 indicates, the replaceability between the CoP and the SoP is confined to a defined boundary as disclosed in accounting control research [83]. Referred to the diminishing effects of marginal deterrence (Section 5.1), an effective strategy to inhibit collusive bidding is finding an effective combination of the certainty and severity of punishment rather than merely choosing one, concurring with the work by Polinsky and Shavell [84].

5.3. Improving the Efficiency of Punitive Measures. In the study, an increase in detection success rate represents an improvement of detection efficiency, depending on an unchanged detection cost level. Based on the four scenarios mentioned above, the success rate of detection is classified as follows: inefficient measures $(k<30.3 \%)$, less efficient measures $(30.3 \% \leq k<31.9 \%)$, neutrally efficient measures $(31.9 \% \leq k<44.1 \%)$, and highly efficient measures $(k \geq 44.1 \%)$. The derivation of these four scenarios paves the way for improving the deterrence effects of the less efficient measures and the neutrally efficient measures.

Regarding the deterrence effects of the less efficient measures, reducing detection costs is not useful enough for rendering a shift to neutrally efficient measures. If the less efficient measures are sometimes be exerted [85], it is vital to include a high detection frequency to ensure the deterrence effects. Therefore, antitrust authorities must conduct 100\% detection. Furthermore, regarding the deterrence effects of the neutrally efficient measures, reducing detection costs helps antitrust authorities to render highly efficient measures. It seems that a longer-lasting of neutrally efficient measures may also inhibit the backlash against collusive bidding. Consequently, this finding indicates that antitrust authorities shall calculate collusive detection costs exactly to improve the deterrence of punitive measures.

\section{Conclusions}

Does a punitive measure prevent collusive bidding in the construction sector? If so, how and to what extent? This study demonstrates that increasing the certainty and severity of punishment can improve collusive bidding deterrence, indicating the usefulness of punitive measures to combat collusive bidding. The deterrence effects are reflective of a diminishing marginal mode. Besides, the certainty and severity of punishment cannot fully replace one for another in deterring collusive bidding. Furthermore, realizing a shift from less efficient measures to neutrally efficient measures shall address the changes in detection costs regarding their deterrence effects. The research findings enlighten antitrust authorities to evaluate the effectiveness of competition policy for the inhibition of collusive bidding. The implication is that antitrust authorities shall strike the trade-off between enhancing punishment and improving policy enforcement capacity.

The study has a few limitations. First, the model considers the effects of punitive measures on collusive bidding inhibition. Future research is recommended to account for more factors such as contract reward [29] and ethics [30]. Second, the case data were subject to the uniqueness of China's construction industry. Model parameters are open for amendment in other national contexts. Third, the study can take into account short-term returns when investigating all actors' decision-making. The model shall be revised to ensure that actors' pursuit of long-term returns is embedded into the decision-making process.

\section{Data Availability}

The data supporting the conclusions of the study can be accessed by request.

\section{Conflicts of Interest}

The authors state that no conflicts exist among all relevant interests.

\section{Acknowledgments}

This work was supported by the National Natural Science Foundation of China (grant no. 71871033) and the $\mathrm{Hu}$ manities and Social Science Foundation of the Ministry of Education of China (grant no. 19YJC630065).

\section{References}

[1] R. C. de Andrade Lima and G. M. Resende, "Using the Moran's I to detect bid rigging in Brazilian procurement auctions," The Annals of Regional Science, vol. 66, no. 2, pp. 237-254, 2020. 
[2] M. J. G. Rodriguez, V. R. Montequin, F. O. Fernandez, and J. M. V. Balsera, "Bidders recommender for public procurement auctions using machine learning: data analysis, algorithm, and case study with tenders from Spain," Complexity, vol. 2020, Article ID 8858258, 20 pages, 2020.

[3] R. Clark, D. Coviello, J.-F. Gauthier, and A. Shneyerov, "Bid rigging and entry deterrence in public procurement: evidence from an investigation into collusion and corruption in Quebec," The Journal of Law, Economics, and Organization, vol. 34, no. 3, pp. 301-363, 2018.

[4] M. Agranov and L. Yariv, "Collusion through communication in auctions," Games and Economic Behavior, vol. 107, pp. 93-108, 2018.

[5] A. D. Pressey and M. Vanharanta, "Dark network tensions and illicit forbearance: exploring paradox and instability in illegal cartels," Industrial Marketing Management, vol. 55, pp. 35-49, 2016.

[6] R. H. Porter and J. D. Zona, "Detection of bid rigging in procurement auctions," Journal of Political Economy, vol. 101, no. 3, pp. 518-538, 1993.

[7] A. Zarkada-Fraser, "A classification of factors influencing participating in collusive tendering agreements," Journal of Business Ethics, vol. 23, no. 3, pp. 269-282, 2000.

[8] A. Hu, T. Offerman, and S. Onderstal, "Fighting collusion in auctions: an experimental investigation," International Journal of Industrial Organization, vol. 29, no. 1, pp. 84-96, 2011.

[9] A. Zarkada-Fraser and M. Skitmore, "Decisions with moral content: collusion," Construction Management and Economics, vol. 18, no. 1, pp. 101-111, 2000.

[10] W. Lo, R. J. Krizek, and A. Hadavi, "Effects of high prequalification requirements," Construction Management and Economics, vol. 17, no. 5, pp. 603-612, 1999.

[11] Q. Zhang, B. L. Oo, and B. T. H. Lim, "Mapping perceptions and implementation of corporate social responsibility for construction firms via importance-performance analysis: paths of improvement," Journal of Management in Engineering, Forthcoming, 2021.

[12] A. G. Dorée, "Collusion in the Dutch construction industry: an industrial organization perspective," Building Research \& Information, vol. 32, no. 2, pp. 146-156, 2004.

[13] S. Gupta, "The effect of bid rigging on prices: a study of the highway construction industry," Review of Industrial Organization, vol. 19, no. 4, pp. 453-467, 2001.

[14] R. Goldstock, M. Marcus, T. Thatcher, and J. J. Jacobs, Corruption and Racketeering in the New York City Construction Industry: The Final Report of the New York State Organized Crime Taskforce, New York University Press, New York, NY, USA, 1989.

[15] Y. Yu, I. Martek, M. R. Hosseini, and C. Chen, "Demographic variables of corruption in the Chinese construction industry: association rule analysis of conviction records," Science and Engineering Ethics, vol. 25, no. 4, pp. 1147-1165, 2019.

[16] X. L. Ding, "The quasi-criminalization of a business sector in China. Deconstructing the construction-sector syndrome," Crime, Law and Social Change, vol. 35, no. 3, pp. 177-201, 2001.

[17] P. X. W. Zou, "Strategies for minimizing corruption in the construction industry in China," Journal of Construction in Developing Countries, vol. 11, no. 2, pp. 15-29, 2006.

[18] R. Hartley, "Fighting corruption in the Australian construction industry: the national code of practice," Leadership and Management in Engineering, vol. 9, no. 3, pp. 131-135, 2009.
[19] C. Krishnan, "Combating corruption in the construction and engineering sector: the role of transparency international," Leadership and Management in Engineering, vol. 9, no. 3, pp. 112-114, 2009.

[20] Z. S. Chen, X. Zhang, R. Rodríguez, W. Pedrycz, and L. Martinez, "Expertise-based bid evaluation for constructioncontractor selection with generalized comparative linguistic ELECTRE III," Automation in Construction, vol. 125, Article ID 103578, 2021.

[21] W. Wils, Is Criminalization of EU Competition Law the Answer?, pp. 117-159, Amsterdam Center for Law and Economics (ACLE) Conference Remedies and Sanctions in Competition Policy, Amsterdam, The Netherlands, 2005.

[22] Z. S. Chen, X. Zhang, W. Pedrycz, X. J. Wang, and M. J. Skibniewski, "Bid evaluation in civil construction under uncertainty: a two-stage LSP-ELECTRE III-based approach," Engineering Applications of Artificial Intelligence, vol. 94, Article ID 103835, 2020.

[23] L. Xiao, Z.-S. Chen, X. Zhang, J.-P. Chang, W. Pedrycz, and K.-S. Chin, "Bid evaluation for major construction projects under large-scale group decision-making environment and characterized expertise levels," International Journal of Computational Intelligence Systems, vol. 13, no. 1, pp. 12271242, 2020.

[24] A. P. C. Chan and E. K. Owusu, "Corruption forms in the construction industry: literature review," Journal of Construction Engineering and Management, vol. 143, no. 8, Article ID 04017057, 2017.

[25] K. Hendricks and R. H. Porter, "An empirical study of an auction with asymmetric information," The American Economic Review, vol. 78, no. 5, pp. 865-883, 1988.

[26] C. M. F. Ho, "Communication makes a corporate code of ethics effective: lessons from Hong Kong," Journal of Construction Engineering and Management, vol. 139, no. 2, pp. 128-137, 2013.

[27] O. Armantier, C. A. Holt, and C. R. Plott, "A procurement auction for toxic assets with asymmetric information," American Economic Journal-Microeconomics, vol. 5, no. 4, pp. 142-162, Nov 2013.

[28] M. S. Robinson, "Collusion and the choice OF auction," The RAND Journal of Economics, vol. 16, no. 1, pp. 141-143, 1985.

[29] Y. Fang, T. P. Benko, M. Perc, H. Xu, and Q. Tan, "Synergistic third-party rewarding and punishment in the public goods game," Proceedings of Mathematical, Physical, and Engineering Sciences, vol. 475, Article ID 20190349, 2019.

[30] V. Capraro and M. Perc, "Mathematical foundations of moral preferences," Journal of the Royal Society, Interface, vol. 18, Article ID 20200880, 2021.

[31] M.-L. Allain, M. Boyer, R. Kotchoni, and J.-P. Ponssard, “Are cartel fines optimal? Theory and evidence from the European union," International Review of Law and Economics, vol. 42, pp. 38-47, 2015.

[32] R. C. Marshall and L. M. Marx, "Bidder collusion," Journal of Economic Theory, vol. 133, no. 1, pp. 374-402, 2007.

[33] A. Llorente-Saguer and R. i. Zultan, "Collusion and information revelation in auctions," European Economic Review, vol. 95, pp. 84-102, 2017.

[34] K. Sherstyuk, "Collusion in private value ascending price auctions," Journal of Economic Behavior \& Organization, vol. 48, no. 2, pp. 177-195, 2002.

[35] M. Reeves-Latour and C. Morselli, "Bid-rigging networks and state-corporate crime in the construction industry," Social Networks, vol. 51, pp. 158-170, 2017. 
[36] C. Beccaria, On Crimes and Punishments, Clarendon Press, Oxford, UK, 1764.

[37] M. Perc, J. J. Jordan, D. G. Rand, Z. Wang, S. Boccaletti, and A. Szolnoki, "Statistical physics of human cooperation," Physics Reports, vol. 687, pp. 1-51, 2017.

[38] A. Szolnoki and M. Perc, "Second-order free-riding on antisocial punishment restores the effectiveness of prosocial punishment," Physical Review X, vol. 7, Article ID 041027, 2017.

[39] G. S. Becker, "Crime and punishment: an economic approach," Journal of Political Economy, vol. 76, no. 2, pp. 169-217, 1968.

[40] D. Husak, Criminal Law Theory, John Wiley and Sons Limited, Hoboken, NJ, USA, 2008.

[41] S. Z. S. Tabish and K. N. Jha, "The impact of anti-corruption strategies on corruption free performance in public construction projects," Construction Management and Economics, vol. 30, no. 1, pp. 21-35, 2012.

[42] R. A. Posner, Antitrust Law: An Economic Perspective, University of Chicago Press, Chicago, IL, USA, 1978.

[43] E. Motchenkova, H. E. D. Houba, and Q. Wen, "Antitrust enforcement and marginal deterrence," SSRN Electronic Journal, vol. 166/1, pp. 1-45, 2011

[44] M. J. G. Bun, R. Kelaher, V. Sarafidis, and D. Weatherburn, "Crime, deterrence and punishment revisited," Empirical Economics, vol. 59, no. 5, pp. 2303-2333, 2020.

[45] I. Ehrlich, "Participation in illegitimate activities: a theoretical and empirical investigation," Journal of Political Economy, vol. 81, no. 3, pp. 521-565, 1973.

[46] A. D. Witte, "Estimating the economic model of crime with individual data," The Quarterly Journal of Economics, vol. 94, no. 1, pp. 57-84, 1980.

[47] C. Cornwell and W. N. Trumbull, "Estimating the economic model of crime with panel data," The Review of Economics and Statistics, vol. 76, no. 2, pp. 360-366, 1994.

[48] S. S. Padhi, S. M. Wagner, and P. K. J. Mohapatra, "Design of auction parameters to reduce the effect of collusion," Decision Sciences, vol. 47, no. 6, pp. 1016-1047, 2016.

[49] P. Bajari and G. Summers, "Detecting collusion in procurement auctions," Antitrust Law Journal, vol. 70, no. 1, pp. 143-170, 2002.

[50] Y. Katsoulacos, E. Motchenkova, and D. Ulph, "Combining cartel penalties and private damage actions: the impact on cartel prices," International Journal of Industrial Organization, vol. 73, Article ID 102604, 2020.

[51] M. A. Bergman, J. Lundberg, S. Lundberg, and J. Y. Stake, "Interactions across firms and bid rigging," Review of Industrial Organization, vol. 56, no. 1, pp. 107-130, 2020.

[52] J. Bentham, An Introduction to the Principles of Morals and Legislation, Clarendon Press, Oxford, UK, 1789.

[53] A. E. Oke, "Causes of collusion among people in construction," in Proceedings of Joint CIB W099 and TG59 International Safety, Health, and People in Construction Conference, Cape Town, South Africa, June 2017.

[54] R. Chotibhongs and D. Arditi, "Analysis of collusive bidding behaviour," Construction Management and Economics, vol. 30, no. 3, pp. 221-231, 2012.

[55] D. A. Graham and R. C. Marshall, "Collusive bidder behavior at single-object second-price and English auctions," Journal of Political Economy, vol. 95, no. 6, pp. 1217-1239, 1987.

[56] D. Imhof, Y. Karagök, and S. Rutz, "Screening for bid riggingdoes it work?" Journal of Competition Law \& Economics, vol. 14, no. 2, pp. 235-261, 2018.
[57] R. Chotibhongs and D. Arditi, "Detection of collusive behavior," Journal of Construction Engineering and Management, vol. 138, no. 11, pp. 1251-1258, 2012.

[58] P. Ballesteros-Pérez, M. C. González-Cruz, A. CañavateGrimal, and E. Pellicer, "Detecting abnormal and collusive bids in capped tendering," Automation in Construction, vol. 31, pp. 215-229, 2013.

[59] J. Wachs and J. Kertesz, "A network approach to cartel detection in public auction markets," Scientific Reports, vol. 9, Article ID 10818, 2019.

[60] S. Joshi and P. L. Vora, "Weak and strong multimarket bidding rings," Economic Theory, vol. 53, no. 3, pp. 657-696, 2013.

[61] M. Huber and D. Imhof, "Machine learning with screens for detecting bid-rigging cartels," International Journal of Industrial Organization, vol. 65, pp. 277-301, 2019.

[62] P. Bajari and L. Ye, "Deciding between competition and collusion," Review of Economics and Statistics, vol. 85, no. 4, pp. 971-989, 2003.

[63] X. Wang, K. Ye, and D. Arditi, "Embodied cost of collusive bidding: evidence from China's construction industry," Journal of Construction Engineering and Management, vol. 147, no. 6, Article ID 04021037, 2021.

[64] V. Krishna, Auction Theory, Academic Press, San Diego, CF, USA, Second edition, 2010.

[65] B. Zhang, Y. Le, B. Xia, and M. Skitmore, "Causes of businessto-government corruption in the tendering process in China," Journal of Management in Engineering, vol. 33, no. 2, pp. $050160221-10,2017$.

[66] M. Motta, Competition Policy: Theory and Practice, Cambridge University Press, Cambridge, UK, 2004.

[67] D. L. Sjoquist, "Property crime and economic behaviors: some empirical results," American Economic Review, vol. 63, no. 3, pp. 439-446, 1973.

[68] W. M. Landes, "Optimal sanctions for antitrust violations," The University of Chicago Law Review, vol. 50, no. 2, pp. 652-678, 1983.

[69] J. M. Connor and R. H. Lande, "Cartels as rational business strategy: crime pays," Social Science Electronic Publishing, vol. 34, no. 2, pp. 427-490, 2012.

[70] S. Colombo, "Product differentiation and collusion sustainability when collusion is costly," Marketing Science, vol. 32, no. 4, pp. 669-674, 2013.

[71] J. Chen and S. Micali, "Collusive dominant-strategy truthfulness," Journal of Economic Theory, vol. 147, no. 3, pp. 1300-1312, 2012.

[72] W. S. Comanor and M. A. Schankerman, "Identical bids and cartel behavior," The Bell Journal of Economics, vol. 7, no. 1, pp. 281-286, 1976.

[73] P. A. G. van Bergeijk, "On the allegedly invisible Dutch construction sector cartel," Journal of Competition Law and Economics, vol. 4, no. 1, pp. 115-128, 2008.

[74] S. F. Schantl and A. Wagenhofer, "Deterrence of financial misreporting when public and private enforcement strategically interact," Journal of Accounting and Economics, vol. 70, Article ID 101311, 2020.

[75] H. Priemus, "Dutch contracting fraud and governance issues," Building Research \& Information, vol. 32, no. 4, pp. 306-312, 2004.

[76] R. Signor, P. E. D. Love, O. Olatunji, J. J. C. B. Vallim, and A. B. Raupp, "Collusive bidding in Brazilian infrastructure projects," Proceedings of the Institution of Civil EngineersForensic Engineering, vol. 170, no. 3, pp. 113-123, 2017. 
[77] J. D'Arcy and T. Herath, "A review and analysis of deterrence theory in the IS security literature: making sense of the disparate findings," European Journal of Information Systems, vol. 20, no. 6, pp. 643-658, 2011.

[78] D. S. Nagin, "Deterrence: a review of the evidence by a criminologist for economists," Annual Review of Economics, vol. 5, no. 1, pp. 83-105, 2013.

[79] B. A. Jacobs, "Deterrence and deterrability," Criminology, vol. 48, no. 2, pp. 417-441, 2010.

[80] A. Chalfin and J. McCrary, "Criminal deterrence: a review of the literature," Journal of Economic Literature, vol. 55, no. 1, pp. 5-48, 2017.

[81] S. Imai and K. Krishna, "Employment, deterrence, and crime in a dynamic model*," International Economic Review, vol. 45, no. 3, pp. 845-872, 2004.

[82] E. Feess, H. Schildberg-Hörisch, M. Schramm, and A. Wohlschlegel, "The impact of fine size and uncertainty on punishment and deterrence: theory and evidence from the laboratory," Journal of Economic Behavior \& Organization, vol. 149, pp. 58-73, 2018.

[83] V. Laux and P. C. Stocken, "Accounting standards, regulatory enforcement, and innovation," Journal of Accounting and Economics, vol. 65, no. 2-3, pp. 221-236, 2018.

[84] A. M. Polinsky and S. Shavell, "On the disutility and discounting of imprisonment and the theory of deterrence," The Journal of Legal Studies, vol. 28, no. 1, pp. 1-16, 1999.

[85] I. Ayres and S. D. Levitt, "Measuring positive externalities from unobservable victim precaution: an empirical analysis of Lojack," The Quarterly Journal of Economics, vol. 113, no. 1, pp. 43-77, 1998. 